\title{
The Role of Pathology and Oncology in the Anatomic-clinical and Biochemical Particulars of the Oral Tumours
}

\author{
VICTOR COSTAN ${ }^{1}$, CRISTIAN CONSTANTIN BUDACU ${ }^{1}$, VLAD DANILA ${ }^{1 *}$, \\ OVIDIU MIHAIL STEFANESCU ${ }^{1 *}$, CORINA CIUPILAN ${ }^{3}$, \\ MIHAELA MONICA SCUTARIU ${ }^{1 *}$, IOAN SARBU ${ }^{2}$, GABRIELA GURAU ${ }^{4}$, \\ VICTORITA STEFANESCU ${ }^{4}$ \\ 1"Grigore T. Popa" University of Medicine and Pharmacy, Faculty of Dental Medicine, 16 Independetei Str., 700115, Iasi, \\ Romania \\ 2"Carol Davila" University of Medicine and Pharmacy, Faculty of Dental Medicine, 37 Dionisie Lupu Str., 020021, \\ Bucharest, Romania \\ 3"Grigore T. Popa" University of Medicine and Pharmacy, Faculty of Medicine, 16 Independetei Str., 700115, Iasi, \\ Romania \\ 4"Dunarea de Jos" University of Galati, Faculty of Medicine and Pharmacy, 47 Domneasca Str., 800008, Galati, Romania
}

\begin{abstract}
Malign tumours of the oral cavity is one of the most frequent types of cancer, ${ }^{-}$mostly in developing regions either in the developed world. The Romanian authorities said that the second cause of death in the world is cancer, as it is only overtaken by cardiovascular diseases. Cancer causes more than 6 million deaths per year (O.S.) - or more than 10\% of all deaths in the world. In Romania, cancer mortality has been around12-15\% of the total number of deaths of various causes over the last decade. After the age of 60, almost one in four people died through cancer. Of all cancers, oral cancer accounts for about 4,5\% and causes $4,2 \%$ of deaths, a percentage that is constantly increasing (PARKIN, STJERNSWARD and MUIR). Oncology is a medical specialty that deals with the diagnosis, treatment and prevention of the disease of human cancer. The oncological examination may suggest the malignant disease (some changes in the history and physical examination of the patient) and the laboratory analysis (markers of tumour) and imaging (mammography, ultrasound, CT, MRI, endoscopy) may bring additional information regarding the presence of the neoplastic process. For the dental pathologyit is indispensable the pathological anatomy for a correct diagnosis and to establish a correct treatment. Although oral cavity is an easily accessible area for clinical examination and more than $80 \%$ of the population often benefit from dental examination, $a$ large part of the cancers developing at this level are diagnosed relatively late to sometimes even considerable size when their treatment is already ineffective. The patients presentthemselves very late for dental clinical examination, in most cases without any symptoms because of the character of the disease in the early stages. Finding the early lesions with carcinogen risk save lives and is correlated with decreased range of risks and best prospective results. We've made this study in the Oral and Maxillo-Facial Surgery Clinic and in the Oncology Clinic in a period of 2 years, between 2017-2019, a number of 146 cases with different oral tumours were solved and followed; of these $49.27 \%$ were men and 50.73\% women.The age average was between 18-65 years and the highest incidence was between 45-62 years. Systemic treatments were administrated and evaluated in all patients.
\end{abstract}

Keywords: dental pathology, oncology, organic lesions, psychic lesions.

\section{Introduction}

The time when a benign lesion has become cancer is hard to determine.Quite rightly, SPIRGLAS says that talking about "beginning in cancer" is a euphemism, and the description is partof the field of

\footnotetext{
*email:vlad.danila@umfiasi.ro; ovidiu.stefanescu@umfiasi.ro; mihaela.scutariu@umfiasi.ro
} 
imagination.In fact, in the early diagnosis we are talking about clinically detectable cancer because cell-level it is very likely that the lesions will occur much earlier.

The morpho functional integrity is the most expected results of the treatment for such lesions [1]. Beyond the limits of the adaptive capacity of the organism, stress sometimes involves disorganizing the personality, disrupting behavioural reactions through repeated stress or cumulative stress, the adaptive resources of the body and the normal means of defence are no longer sufficient and the adaptive capacity is exceeded [2]. By intervening in the convergence of internal and external factors, in the dynamic equilibrium structure, the disease requires the adoption of a new type of behaviour, a form of substitution of the behaviour that we call normal.

In order to carry out an early diagnosis of oral cancer, the authors recommend three conditions: a high suspicion index, a systematic and careful examination and a good knowledge ofclinical onset events.A correct and complete examination of the patient's or tumour formation during routine clinical examination must specify its main variables: measured tumour size as accurately as possible, consistency, mobility, extension to neighbouring structures. During routine clinical examination in the dental practice, the cervical region or cervical nodal formation is frequently neglected. These formations are sometimes regional lymphatic metastases that represent the first clinical manifestation of oral cancer.

Diagnosis of the existence or non-existence of regional cervical metastases is essential for establishing the prognosis and treatment plan. The objectives that we considered important and have taken as a benchmark for achieving the intended purpose of assessing early diagnostic methods in oral cancer are: clinical examination, the value of the toluene blue vital staining test (RICHART test), cytologic diagnostic, histopathological examination, electronic microscopyinvestigations.

With regard to clinical manifestations it should be noted that there are no characteristic clinical manifestations in the early stages of oro-maxillo-facial cancer. In the initial phase, the cancer lesions are painless and have a banal aspect: a red or white stain, an erosion, ulceration or superficial crack, persistent or recidivism located at the mucosa, covered by a rind or blood-on-the-touch; appearance of an ulceration; a small prominent formation with a keratinized area or a small papilloma; a painless node, free of inflammatory phenomena, submucous, subcutaneous, in the thickness of the soft parts or main salivary glands; a discrete deformation of the bone plan; dental mobility or toothache which cannot be explained by dental-periodontal lesions or alveolar ridge, extremely rare areas of hypo or anesthesia, especially "painful anesthesia", trigeminal nerve branches that have intra-bone paths $[1,2]$.

These manifestations could be: actinic cheilitis, Paget's disease, flat lichen and leucoplakia with their various etiopathogenic forms and to some extent the epulis [3]. Actinic cheilitis it is known as superficial inflammatory lesions of the lipslocalized at the level of the labial mucosa. It is a premalignant keratosis of the lip that is produced by the chronical exposure to the sun.Microscopic:at this level it can be seen atrophic or hypertrophic lesions with hyperand para keratosis; the cells are atypical and in disorder. [4].

Paget's disease of the lips Clinically, the patient has bone deformities, pain, functional impotence; the risk of pathological fractures and osteosarcomas are increased. Increased turbidity of bone metabolism results in increased serum alkaline phosphatase level [5].

Lichen planus it is a chronical and inflammatory disease of the oral mucosa. It appears frequently on the oral part of the check, the edge of the tongue and sometimes on the gingiva or even lips. This disease has three forms and it is one of the premalignant lesions ( sometimes turns into epidermoid carcinoma ).

Leucoplakias:In some patients the entire aspect of red lip appears altered, with the atrophic epithelium, cracked, dry or tending to decipher, wearing the clinical picture of "actinic cheilitis" (desquamative) [6].

Epulis: It is to be noted that at alveolar process level, carcinoma can also debut in the clinical form of epulis, rather frequent benign lesion. For this reason, whenever surgical procedures of such formations are made, anatomical pathological examination is mandatory. 
As dysembrioplastic tumours we mention: the hamartoma, is a noncancerous tumorlike malformation made up of an abnormal mixture of cells and tissues. It is considered a developmental error and can occur at a number of sites like oral cavity where the thyroid follicles are localized in the tongue [7].

Coristoma is a tumorlike made by normal tissue in abnormal localisation ( at the level of oral cavity sometimes the glandular tissue of the tongue is replaced by cartilaginous or osseous tissue) .

Branchial cystisa cavity, a congenital remnant from embryologic development. It is present one side of the neck and is located just in front of the large angulated muscle (sternocleidomastoid). The cyst is a smooth, soft and nontender structure.

Papillary cyst adenolymphomais the next common tumor to the pleomorphic adenoma affecting exclusively parotid gland. Microscopic we can see a double layer of epithelial cells resting on dense lymphoid stroma, cystic spaces narrowed by polypoid projections of lymphoepithelial elements, surface palisading of oncocyte columnar cells with underlying discontinuous basal cells, occasional features are cilia, squamous metaplasia associated with infarct-like necrosis, mast cells, dendritic cells, mucin secreting cells, sebaceous cells, no myoepithelial component [8].

Polymorphic adenomais benign triphasic salivary gland neoplasm composed of ductal cells, myoepithelial cells and chondromyxoid stroma.

The oncocytomais a benign tumor composed of oncocytes, also called oxyphilic adenoma andusually appear in parotid gland mass, also submandibular gland or minor salivary glands

Follicular cystis adevelopmental odontogenic cyst that originates by separation of dental follicle from around the crown of an unerupted tooth,also called dentigerous cyst.Diagnosis requires correlation with radiographs or knowledge of radiographic findings

Ameloblastoma is a rarebenign tumor that develops most often in the jaw near the molars. It begins in the cells that form the protective enamel lining on your teeth. This tumor can be very aggressive, growing into the jawbone and causing swelling and pain. Very rarely, ameloblastoma cells can spread to other areas of the body, such as the lymph nodes at thelevel of the neck and lungs[9].

Theoncologist specialized in evaluating and investigating cancer patients, in administering and evaluating systemic treatments including chemotherapy, endocrinotherapy, biological therapies, including supportive and palliative treatments, has become subject to continuous pressure [10,11].The development of new agents and protocols is ongoing and requires extensive randomised multi-centre studies to determine efficacy before they are introduced.

We have tried to synthesize their clinical and morphological characters as well as the current concerns of researchers, in finding markers that have a predictive value for the malignant transformation potential of these lesions. Oral cancer is now still a serious problem for every people and it is well stated that early detection and recognition of injuries with a malignancy potential, it provides a good prognosis of this fearful disease [12].

When we talk about malignant tumor we talk about frequency: the lip cancer (localised more in the lower lip); this type is commonly spinocellular epidermoid carcinoma. The metastasis of this type is localised in submandibular lymph ganglions. In some cases can be bilateral because the submental lymphatic pathways are crossed.

The other types of malignant tumours are: the tongue cancer, the malignant melanoma of the lips, the adenocarcinoma (parotid gland), osteosarcoma of the maxilla (the osteolytic form). All those types listed above have severe evolution with the invasion of the bone and metastasis of the lungs. When we talk about vesselswe remind you of the malignant hemangiopericytoma and hemangiosarcomawith severe complications and difficulties in phonation and feeding [17-20]. Metastasismost commonly occurs by way of the bloodstream or the lymphatic system. Just like normal cells, cancer cells must have a blood supply in order to function. They have access to the bloodstream just as healthy cells do. Once in the bloodstream, the cancer cells now have access to every portion of the body. The lymphatic system has its own channels throughout the body like the circulatory system, through which a malignant cell can travel. Once metastasis to the lymphatic system has occurred, the prognosis for cure 
drops significantly.Oral cancer can spread differently depending on where in the mouth it starts. If oral cancer spreads, it can spread to the following:other parts of the mouth, muscle surrounding the mouth, called cervical lymph nodes, the upper or lower jawbone, skin on the face, salivary glands, liver, lungs, distant bone ( base of the skull, spine etc.), brain [21-24]. When the metastatic nodules are at the bone level, spontaneous fractures can happen. The same in case of osteoradionecrosis because of radiotherapy and related to its vascularization [25-27].

\section{Material and method}

The study included 146 patients with oral cancer diagnosed and treated in the Oncology Clinic and the Clinic of Oral and Maxillo-Facial surgery in a period of 2 years, between 2017-2019. These cases, with different oral tumours were solved and followed; of these $49.27 \%$ were men and $50.73 \%$ were women (Figure 1). The age average was between 18-65 years and the highest incidence was between 45-62 years. Systemic treatments were administrated and evaluated in all patients.

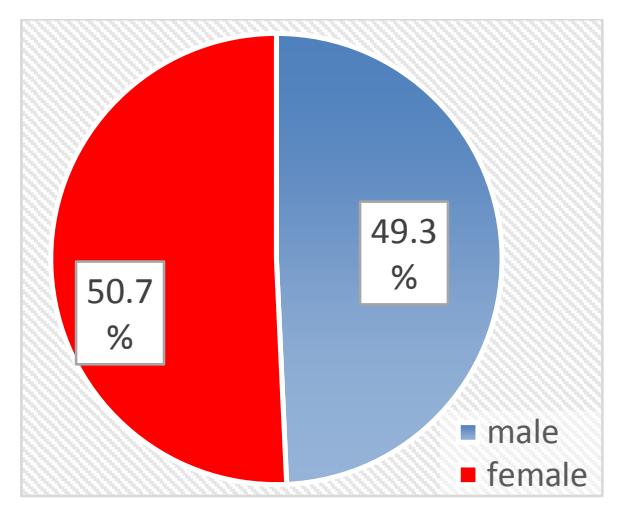

Figure 1. Distribution by gender of cases with different oral tumours

\section{Results and discussions}

In $25 \%$ of the studied tumours, the treatment was surgical and, in some cases, it was recommended to perform radical neck dissection as well as postoperative radiotherapy. The evolutionafter surgery differs depending on the degree of anaplasia of the lesion: those with high degree it presents with local metastases and recurrences in the first 5 years after the resection of the primitive tumour in $60 \%$ of cases. The surgical procedures are illustrated in Figure 2 and the choice of the surgical treatment was related to the size and infiltration of the tumour - radical resection of the tumour with preservation of the anatomical structures and bone resection $-29.16 \%$. If the existence of positive lymph ganglions for the tumour is clinically suspected, radical neck dissections was indicated $-6.25 \%$.

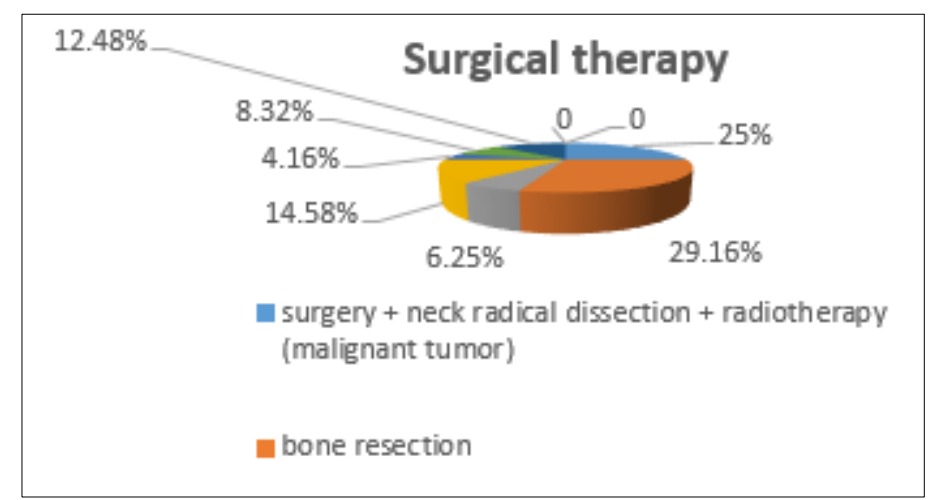

Figure 2. Distribution of surgical therapy 
Literature draws attention to another important element for the prognosis, namely the large number of patients presenting during the first consultation with lesions in advanced stages (stage III and IV) - a fact that is encountered in all countries in the world, but especially in developing countries. For these reasons, with all the progress made in the diagnosis, treatment and rehabilitation of patients, the survival rate over the last 30-40 years has not improved, survival at 5 years is $80 \%$ for lip cancer and less than $30 \%$ for oral cavity cancer. The progress made in recent years in the treatment of oral mucosa

cancer mainly relates to reconstructive techniques which increase the quality of life of the sick but not the survival rate.

Dentists play a critical role in the management of oral cancer, from the detection of premalignant lesions, early detection of oral cancer, management of the oral cancer patient's dentition both prior to and post definitive treatment, surveillance of recurrent or new primary tumours in conjunction with the treating specialist, and rehabilitation of missing teeth in con- junction with the treating maxillofacial surgeon and prosthodontist.

Oral carcinomas are the most frequent and severe malign tumours of the oral mucosa. Therefore, oral cancer represents a compulsory permanent focus of any dentist. In order to asses this diagnosis, clinical and histopathological investigations could be coupled with a mandatory cytological examination and computed tomography.

The physical reception is related to the psychic reactivity and the personality of the subject, since the human being involves a series of internal, latent, social, family, sexual conflicts, whose conflicting energy awaits an opportunity to overflow. The dysfunction of the stomatognathic system thus constitutes a point of departure of such an imbalance.

\section{Conclusions}

Oral mucosa can be the site of highly varied lesions with a large clinical and histological polymorphism. The differentiation between a benign lesion and a malignant onset lesion is extremely difficult to determine only by clinical examination. For this reason, we believe that it is necessary to remove the presumed causal local factors, to introduce non-specific anti-inflammatory treatment, but also to have the patient subject under compulsory supervision. If after 10-14 days the lesions remain, the patient will be directed to a specialized centre.

With regard to clinical manifestations it should be noted that there are no characteristic clinical manifestations in the early stages of oro-maxillo-facial cancer.Oral cancer is a challenging disease with high mortality rates; dentists and dental specialists play a critical role at all stages in the management of patients.Although the role of the dental practitioner in the early diagnosis of oral mucosa cancer is of paramount importance by collating all clinical data and the results of paraclinical scans, he remains an important member of a complex and specialized team of maxillo-facial surgery, anatomypathologist, radiologist, oncologist.

The physician's behaviour towards his patient must be modelled according to the patient's particularities, from the point of view of the general somatic state, of the mental state at the intellectual level and according to the level of culture, as well as the type of reaction of the sick man.

\section{References}

1.ADAMS VR., De REMER D, HOLDSWORTHMT.Guide to cancer Therapeutic regimens Merck Oncologz, 2010.

2.GUNERI P, EPSTEIN JB. Late stage diagnosis of oral cancer: components and possible solutions. Oral Oncol. 2014;50:1131-1136

3.BUCUR, A., NAVARRO VILA, C., LOWRY, J., ACERO, J.: Compendiu de Chirurgie Oro Maxilo - Faciala. vol. 1 and vol. 2, Q Med Publishing, 2009, Bucuresti. I : 223 - 228.

4.CASCIATO DA, TERRITO MC, ed.Manual of clinical oncology 7th edition, Philadelphia:Wolters Kluwer/Lippincott Williams \&Wilkins, 2012:46-99. 
5.TSC WONG, D WIESENFELD ; Oral Cancer , Australian Dental Journal 2018; 63:(1 Suppl): S91S99.

6.LEON X, MARTINEZ V, LOPEZ M, et al. Second, third, and fourth head and neck tumors. A progressive decrease in survival. Head \& neck. 2012;34(12):1716-1719.

7.BROCKLEHURST P, KUJAN O, O’MALLEY LA, OGDEN G, SHEPHERD S, GLENNY AM. Screening programmes for the early detection and prevention of oral cancer. Cochrane Database Syst Rev. 2013;11:Cd004150.

8.ROBBINS KT, FERLITO A, SHAH JP, et al. The evolving role of selective neck dissection for head and neck squamous cell carcinoma. European archives of oto-rhino-laryngology : official journal of the European Federation of Oto-Rhino-Laryngological Societies. 2013;270(4):1195-1202

9.***Woelfel's Dental Anatomy: Its Relevance to Dentistry. 2011.

10.EARAR, K; BICA, C.; CERGHIZAN, D.; et al., The Role of Functional Polymers in the Optimization of the Acrylic Biomaterials Used in Removable Prosthetic Restoration III. Behaviour of the adhesive used for the multilayer consolidation, Mat. Plast., 53, (3), 2016, 512

11.ANCUTA, C., POMIRLEANU, C., MAXIM, R.; et al.Clinical Relevance of Rituximab Immunogenicity in Rheumatoid Arthritis A pilot study, Rev.Chim., 67, (12), 2016, 2573

12.SKEEL RT, KHLEIF SN ed. Handbook of cancer chemotherapy 8 th edition, Philadelphia:Wolters Kluwer-Lippincott Williams\&Wilkins, 2011.

13.CIURCANU, OE ; FORNA, DA; POPA, C; SCUTARIU, MM.; Implementation of methods of loco-regional anesthesia in dental surgery. RJOR, 2017 Volume: 9, 4, Pages: 120-127

14.MURARIU, A., FORNA, AGOP, D., MANOLACHE, F., et al.,Assessment of the oral health risk factors in young people Romanian journal of oral rehabilitation, 9 (3) ,2017, Pg: 48-54

15.EARAR, K., GRADINARU,

,S., PARIZA,G., et al., Effect of the Sterilization Procedures of Different Surgical Meshes for Abdominal Surgery, Rev.Chim., 68, (8), 2017, 1868

16.CIURCANU, O; CIUPILAN, C; SALCEANU, M; MELIAN, A; FORNA, D.A; SCUTARIU, M.M., Particularities of the dental treatment strategy in geriatric patients, RJOR, 2018 Volume: 10, 1, Pages: 108-113,

17.VASINCU, D., IANCU, R.I., CHELARU, L., STOLERIU, G., COSTULEANU, M., Biochemical effects of some endoplasmic reticulum stress inducers on mesenchymal stem cells in vitro, Rev.Chim., (69), 6, 2018, 1570

18.FRETER, C.E., PERRY, M.C., Principles of chemotherapy În Perry MC, ed The chemotherapy source book 5th edition, Wolters Kluwer/Lippincott Williams \&Wilkins, 2012:46-99.

19.LUPUSORU, R.V., TOPOR, G., MIRON, I.C., et al., Chemical Factors which Prompt Oral Pathological Phenomena In Some Nutrition Diseases, Rev.Chim., 70, (5), 2019, p. 1884

20.SCUTARIU, M.M.; MACOVEI, G.; CIURCANU, O.E.L, SURDU, A.; FORNA, N. C. Contributions to the characterization of biocenosis complex of the ecosystem in the oral cavity, The Medical-Surgical Journal, 2017, 121, vol. 4, pg. 801-805

21.DASCALU, C.G., ANTOHE, M.E., GOLOVCENCU L., et al.,Interaction Schemes for the Analysis of Combined Action of Risk Factors,2017 IEEE International Conference on e-health and Bioengineering Conference (EHB) Book Series: E-Health and Bioengineering Conference, 2017, Pages: 462-465

22.SCUTARIU, M.M.; DANILA, V.; CIUPILAN, C.; CIURCANU, O.E ., Semiology of the Pain Syndrome - Identifying the Ideal Methods of Locoregional Anesthesia Based on Their Rationale and Features; Rev.Chim., 68, (10), 2017, 2373

23.TATARCIUC, D., VASINCU, D., STOLERIU, G., IANCU, R.I, COSTULEANU, M., Biochemical effects of Intraliposomal angiotensins on isolated vascular smooth muscle cells, Rev.Chim., 69, 2018, p.1187

24.SAVEANU, C.I., FORNA, N.C., DANILA,I.etal.,Management attitudes of dentists in dental offices, Romanian Journal of Oral Rehabilitation, 10(4), 2018, pg.149-156 
25. BUDACU, C.C.; IOANID, N.; ROMANEC, C.; et al .Dental Inclusion of Canine and Wisdom Tooth in Orthodontics Chemical Necroses, Rev.Chim., 69, (8), 2018, 2191

26.TRUS, C.; MUNTEANU, M.; DIACONU, G.; et al.Venous thrombectomy - treatment of enteromesenteric near total venous acut infarct, CHIRURGIA Volume: 105 Issue: 3, 2010, Pages: 415418

27.SIEGEL R, MA J, ZOU Z, et al. Cancer statistics, 2014. CA: a cancer journal for clinicians. 2014;64(1):9-29.

Manuscript received: 20.02 .2020 